\title{
FIRST DIRECT OBSERVATION OF REVERSIBLE OXYGEN ADDITION TO A CAROTENOID-DERIVED CARBON-CENTERED NEUTRAL RADICAL
}

\author{
Ali El-Agamey ${ }^{1}$ and David J McGarvey* \\ School of Physical and Geographical Sciences, Keele University, Keele, Staffordshire, \\ ST5 5BG, UK. ${ }^{1}$ Permanent address: Chemistry Department, Faculty of Science, New \\ Damietta, Damietta, Egypt.
}

Scheme S1. Reaction scheme postulated by Burton and Ingold ${ }^{5}$.

Figure S1. Transient spectrum of $\mathrm{PhS}^{\bullet}$ obtained following $355 \mathrm{~nm}$ laser photolysis of $\mathrm{PhS}$ $\mathrm{SPh}\left(\sim 8 \times 10^{-3} \mathrm{M}\right)$ in benzene (air-saturated, laser energy $\left.=10 \mathrm{~mJ}\right)$.

Figure S2. Kinetic absorption profile $(460 \mathrm{~nm})$ of $\mathrm{PhS}^{\bullet}$ obtained following $355 \mathrm{~nm}$ laser photolysis (laser energy $=10 \mathrm{~mJ})$ of PhS-SPh $\left(\sim 8 \times 10^{-3} \mathrm{M}\right)$ in air-saturated benzene. Inset shows, for comparison, the decay of $\mathrm{PhS}^{\bullet}$ for a laser energy of $\sim 1 \mathrm{~mJ}$, which is a typical laser energy used when the carotenoid is present and thus shows the intrinsic decay of $\mathrm{PhS}^{\bullet}$ under the experimental conditions employed.

Figure S3. The growth of the transient absorption band at $470 \mathrm{~nm}$ observed at $0.17,14$, 39, 99, $217 \mathrm{~ms}$ following $355 \mathrm{~nm}$ laser photolysis (laser energy $\sim 1.3 \mathrm{~mJ}$ ) of PhS-SPh ( 8 $\left.\times 10^{-3} \mathrm{M}\right)$ in the presence of $77 \mathrm{DH}\left(\sim 2 \times 10^{-5} \mathrm{M}\right)$ in benzene. The inset shows a plot of the dependence of the observed first order rate constant $\left(\mathrm{k}_{\mathrm{obs}}\right)$ for formation of PhS-77DH. at $470 \mathrm{~nm}$ on $[77 \mathrm{DH}]$ from which the reaction rate constant was determined.

Figure S4. The influence of temperature on the normalized transient profiles of PhS$77 \mathrm{DH}^{\circ}$ at $470 \mathrm{~nm}$ obtained following $355 \mathrm{~nm}$ laser excitation (laser energy $=1.3 \mathrm{~mJ}$ ) of PhS-SPh $\left(\sim 8 \times 10^{-3} \mathrm{M}\right)$ in the presence of $77 \mathrm{DH}\left(\sim 2 \times 10^{-5} \mathrm{M}\right)$ in argon-saturated benzene solution.

Figure S5. Kinetic absorption profiles for $\mathrm{PhS}-77 \mathrm{DH}^{\bullet}$ at $470 \mathrm{~nm}$ obtained at three different temperatures ((A) $323 \mathrm{~K},(\mathrm{~B}) 330 \mathrm{~K}(\mathrm{C}) 338 \mathrm{~K})$ and showing biexponential fits with residuals. The traces were obtained following $355 \mathrm{~nm}$ laser photolysis of $\mathrm{PhS}-\mathrm{SPh}(\sim 4 \times$ $\left.10^{-3} \mathrm{M}\right)$ in the presence of $77 \mathrm{DH}\left(\sim 2 \times 10^{-5} \mathrm{M}\right)$ in air-saturated benzene solution (laser energy $=1.3 \mathrm{~mJ}$ ).

Figure S6. Reaction scheme illustrating terminal oxygen addition (top) and an example of non-terminal oxygen addition (bottom).

Figure S7. A plot of In $\mathrm{K}$ versus $1 / \mathrm{T}$ for the reversible addition of oxygen to $\mathrm{PhS}-77 \mathrm{DH}^{\bullet}$ in benzene (air saturated, $1.3 \mathrm{~mJ}$ ).

Figure S8. Arrhenius plot for the $\beta$-fragmentation reaction of $\mathrm{PhS}-77 \mathrm{DH}-\mathrm{OO}{ }^{\circ}$ generated from $355 \mathrm{~nm}$ laser photolysis of PhS-SPh $\left(\sim 4 \times 10^{-3} \mathrm{M}\right)$ in the presence of 77DH $(\sim 2 \times$ $10^{-5} \mathrm{M}$ ) in air-saturated benzene (laser energy $=1.3 \mathrm{~mJ}$ ).

Figure S9. Transient difference absorption spectrum obtained following $355 \mathrm{~nm}$ laser photolysis (laser energy $\sim 4 \mathrm{~mJ})$ of an air-saturated benzene solution of PhS-SPh $(\sim 8 \times$ $\left.10^{-3} \mathrm{M}\right)$ in the presence $\beta$-CAR $\left(\sim 3 \times 10^{-5} \mathrm{M}\right)$. 
Figure S10. Kinetic absorption profiles at $540 \mathrm{~nm}$ obtained following $355 \mathrm{~nm}$ laser photolysis (laser energy $\sim 5 \mathrm{~mJ}$ ) of benzene solutions of PhS-SPh $\left(\sim 8 \times 10^{-3} \mathrm{M}\right)$ in the presence $\beta$-CAR $\left(\sim 3 \times 10^{-5} \mathrm{M}\right)$ at various oxygen concentrations (argon-saturated, airsaturated, oxygen-saturated). The inset shows a plot of the pseudo-first order rate

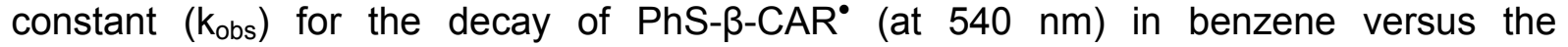
concentration of oxygen.

Table S1. Values of $A_{1}, A_{2}, k_{1}, k_{-1}, k_{o b s(1)}, k_{o b s(2)}, K$, and oxygen concentrations at different temperatures.

${ }^{*}$ Corresponding author

e-mail: d.j.mcgarvey@chem.keele.ac.uk

Fax: +44 1782712378 


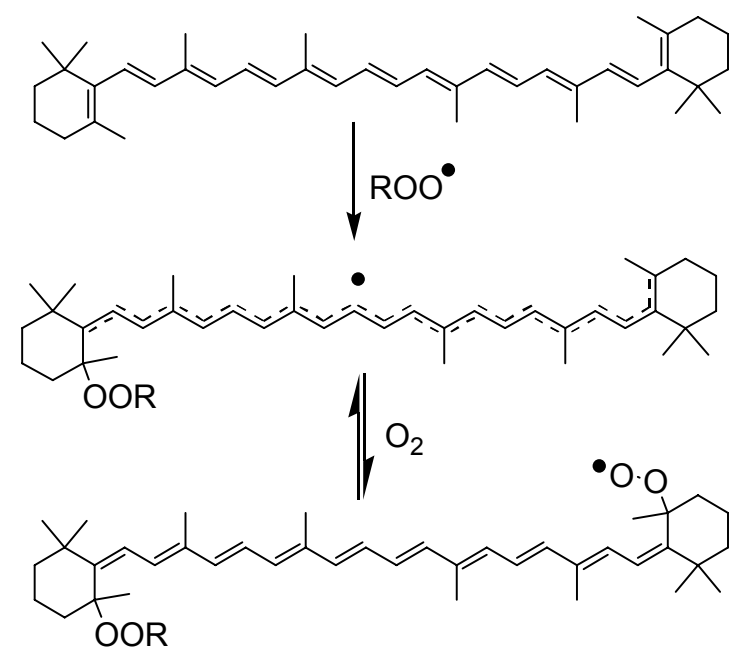

Scheme S1. Reaction scheme postulated by Burton and Ingold ${ }^{5}$. 


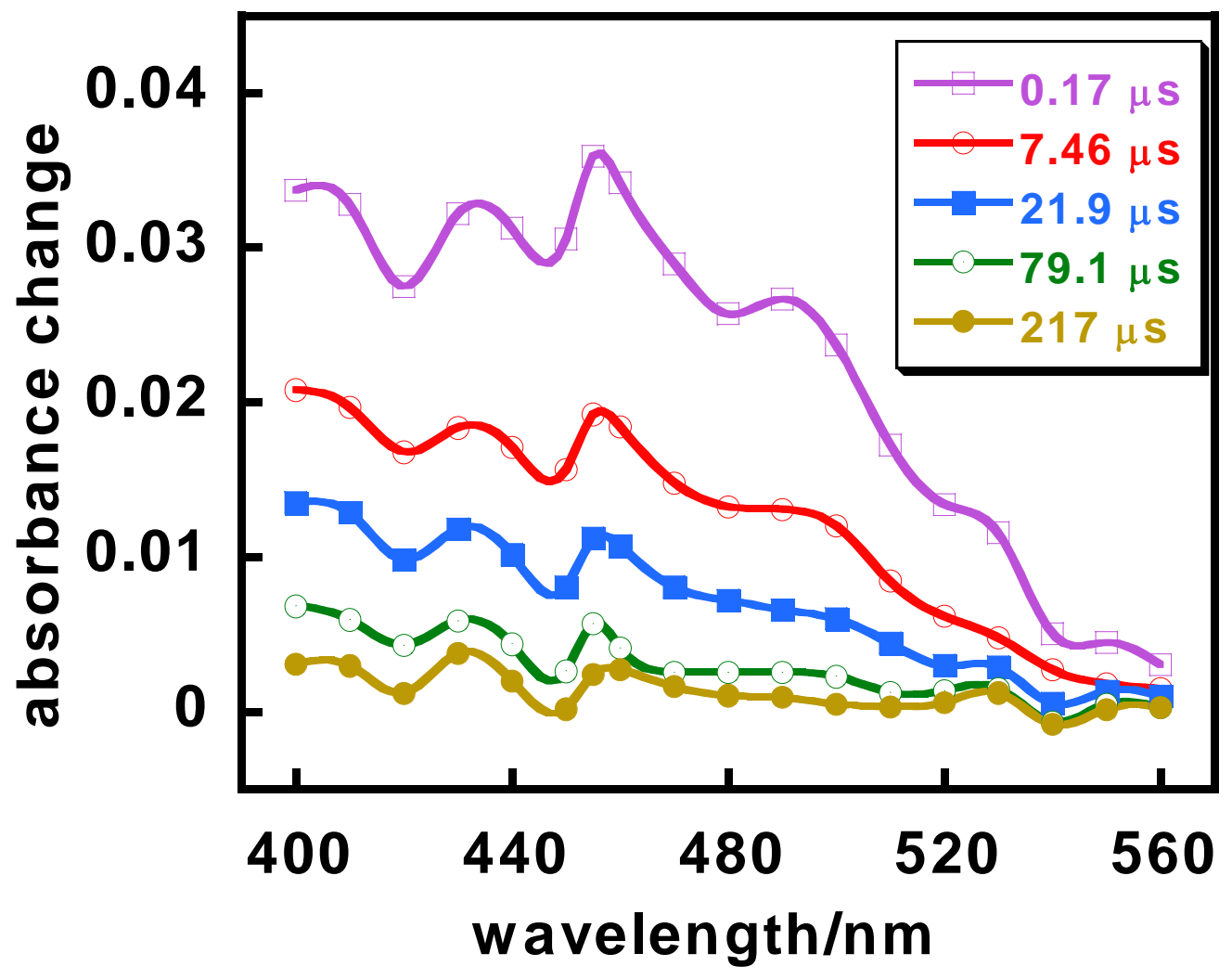

Figure S1. Transient spectrum of $\mathrm{PhS}^{\bullet}$ obtained following $355 \mathrm{~nm}$ laser photolysis of $\mathrm{PhS}$ $\mathrm{SPh}\left(\sim 8 \times 10^{-3} \mathrm{M}\right)$ in benzene (air-saturated, laser energy $\left.=10 \mathrm{~mJ}\right)$. 


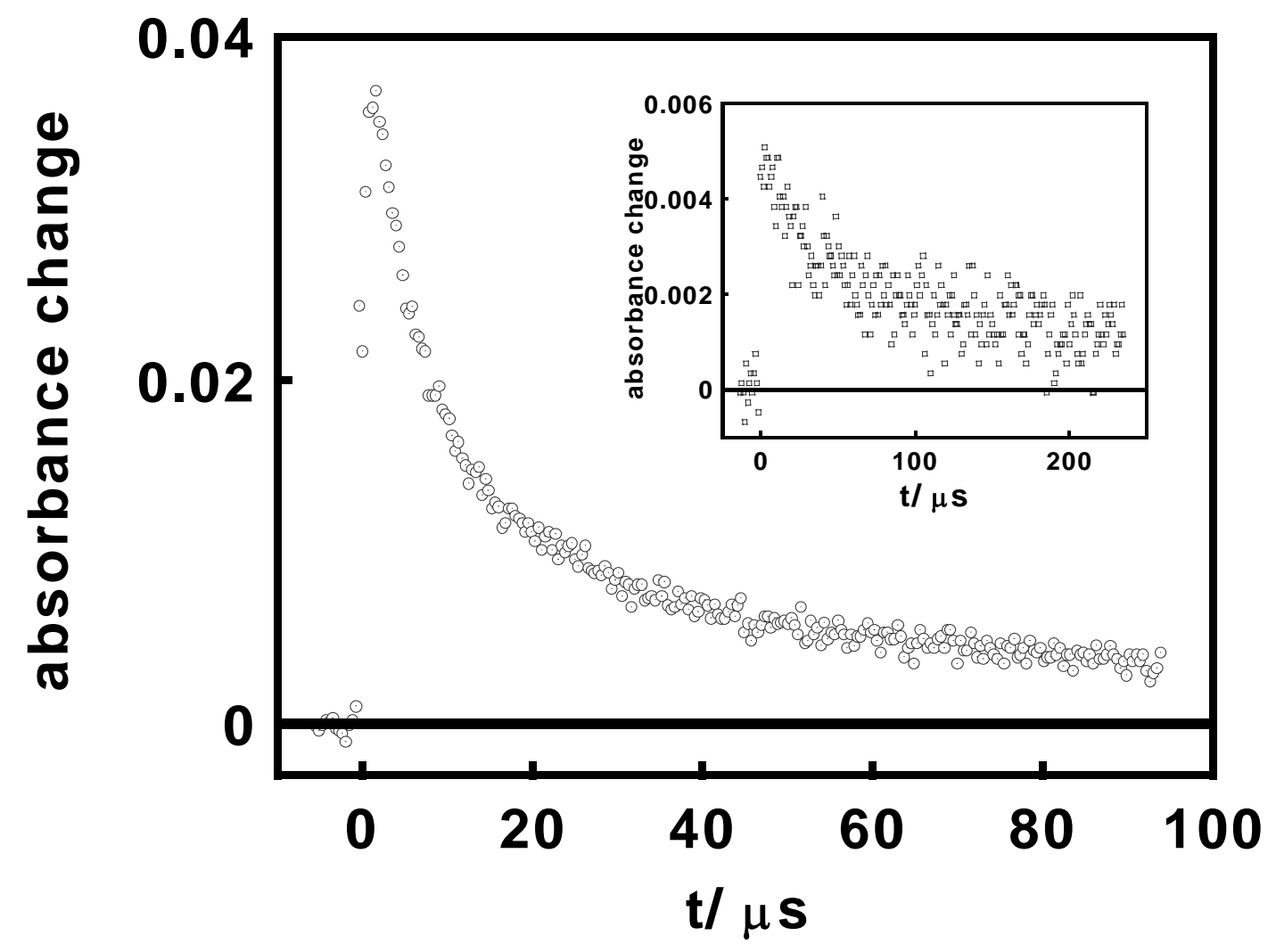

Figure S2. Kinetic absorption profile $(460 \mathrm{~nm})$ of $\mathrm{PhS}^{\bullet}$ obtained following $355 \mathrm{~nm}$ laser photolysis (laser energy $=10 \mathrm{~mJ}$ ) of PhS-SPh $\left(\sim 8 \times 10^{-3} \mathrm{M}\right)$ in air-saturated benzene. Inset shows, for comparison, the decay of $\mathrm{PhS}^{\bullet}$ for a laser energy of $\sim 1 \mathrm{~mJ}$, which is a typical laser energy used when the carotenoid is present and thus shows the intrinsic decay of $\mathrm{PhS}^{\bullet}$ under the experimental conditions employed. 


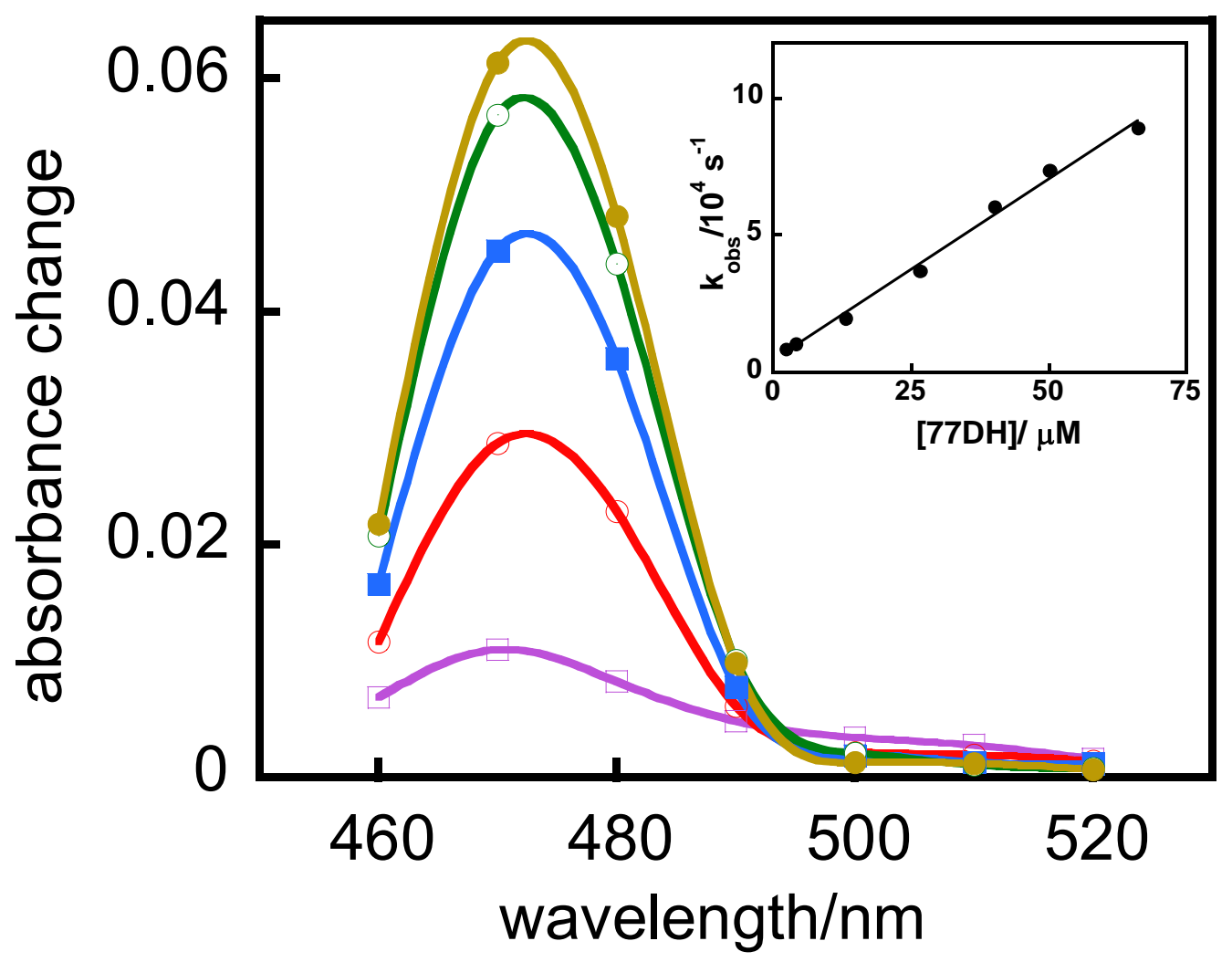

Figure S3. The growth of the transient absorption band at $470 \mathrm{~nm}$ observed at $0.17,14$, 39, 99, 217 ms following $355 \mathrm{~nm}$ laser photolysis (laser energy $\sim 1.3 \mathrm{~mJ})$ of PhS-SPh $(\sim 8$ $\times 10-3 \mathrm{M})$ in the presence of 77DH $(\sim 2 \times 10-5 \mathrm{M})$ in benzene. The inset shows a plot of the dependence of the observed first order rate constant (kobs) for formation of PhS$77 \mathrm{DH} \cdot$ at $470 \mathrm{~nm}$ on $[77 \mathrm{DH}]$ from which the reaction rate constant was determined. 


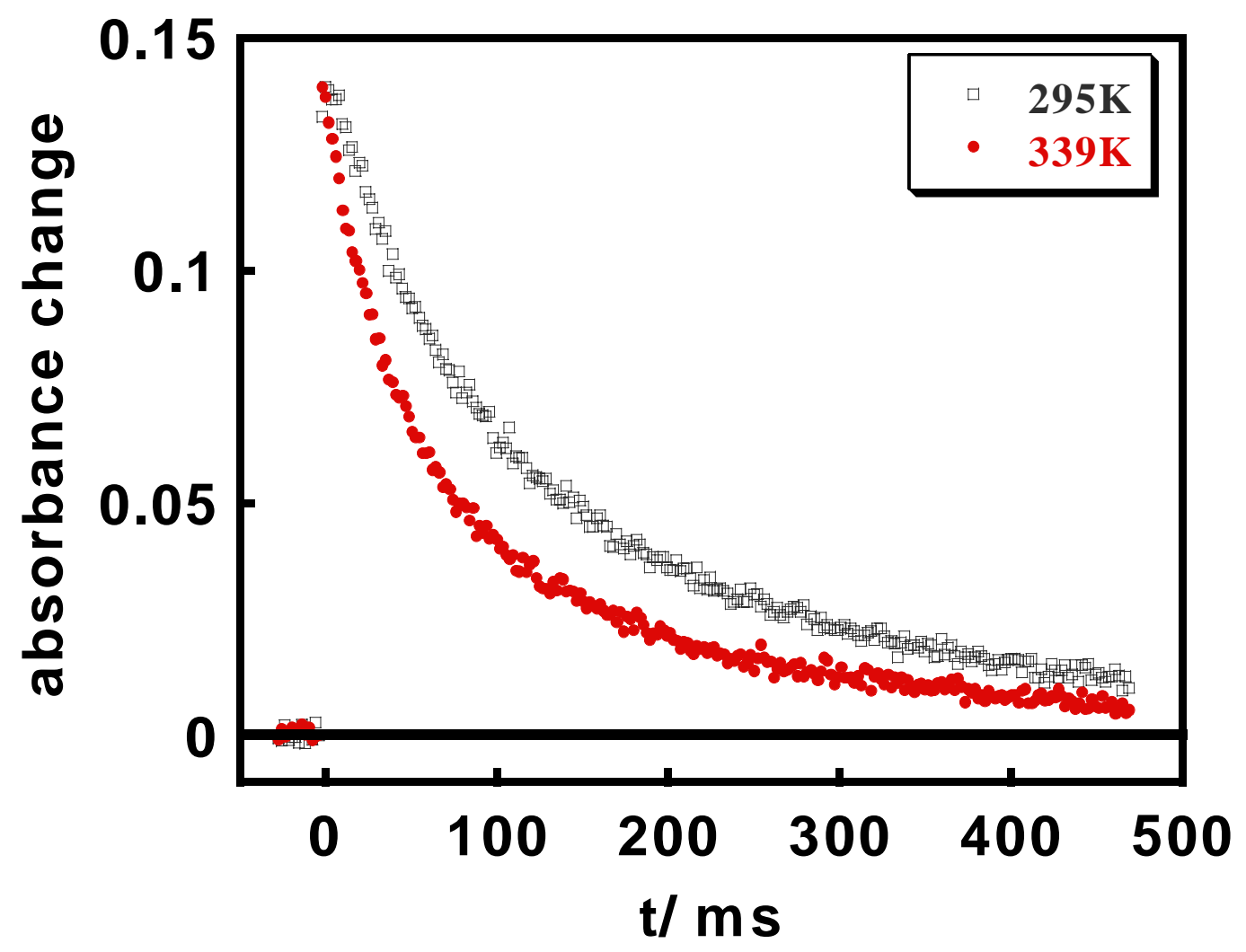

Figure S4. The influence of temperature on the normalized transient profiles of PhS$77 \mathrm{DH}^{\bullet}$ at $470 \mathrm{~nm}$ obtained following $355 \mathrm{~nm}$ laser excitation (laser energy $=1.3 \mathrm{~mJ}$ ) of PhS-SPh $\left(\sim 8 \times 10^{-3} \mathrm{M}\right)$ in the presence of 77DH $\left(\sim 2 \times 10^{-5} \mathrm{M}\right)$ in argon-saturated benzene solution. 


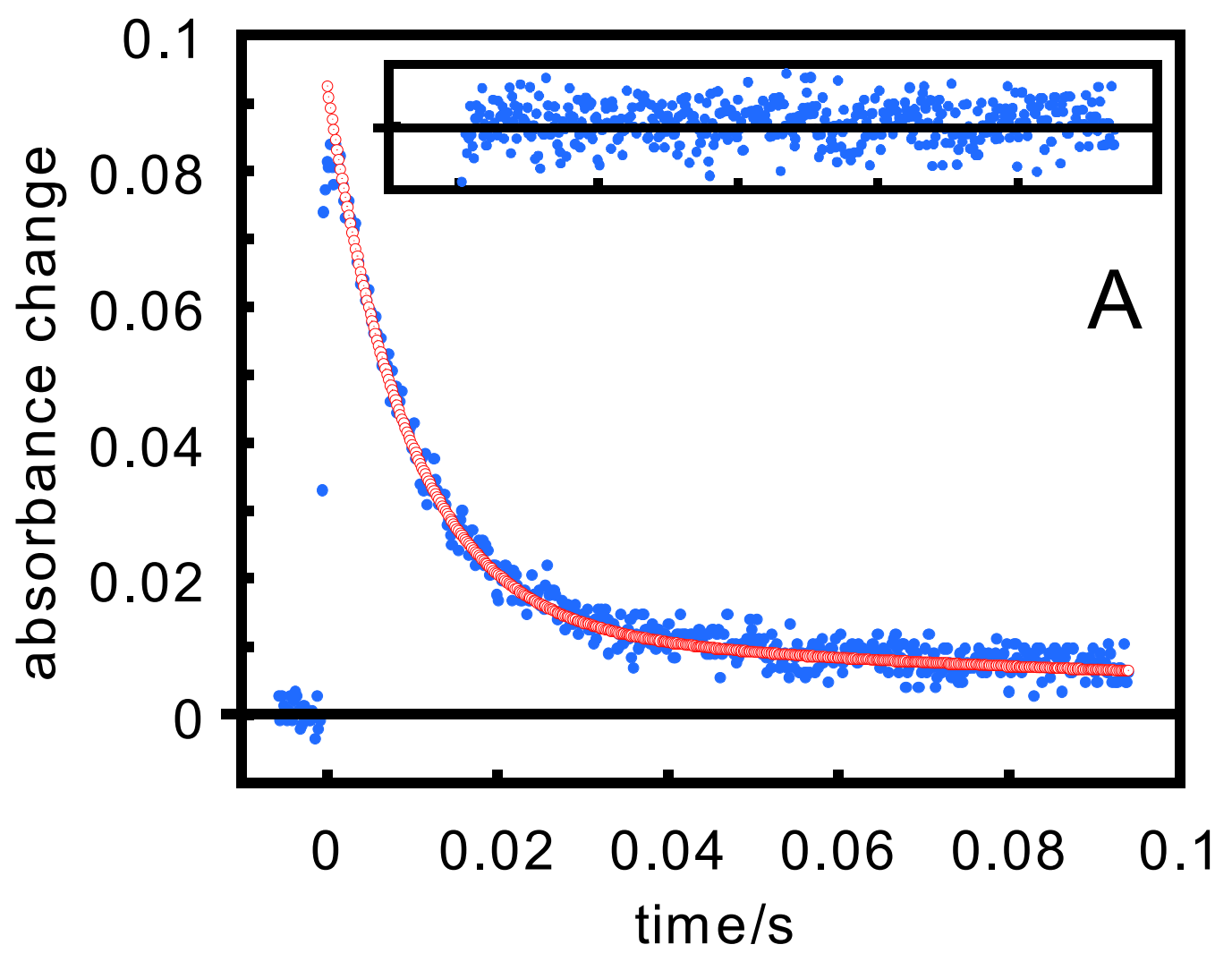




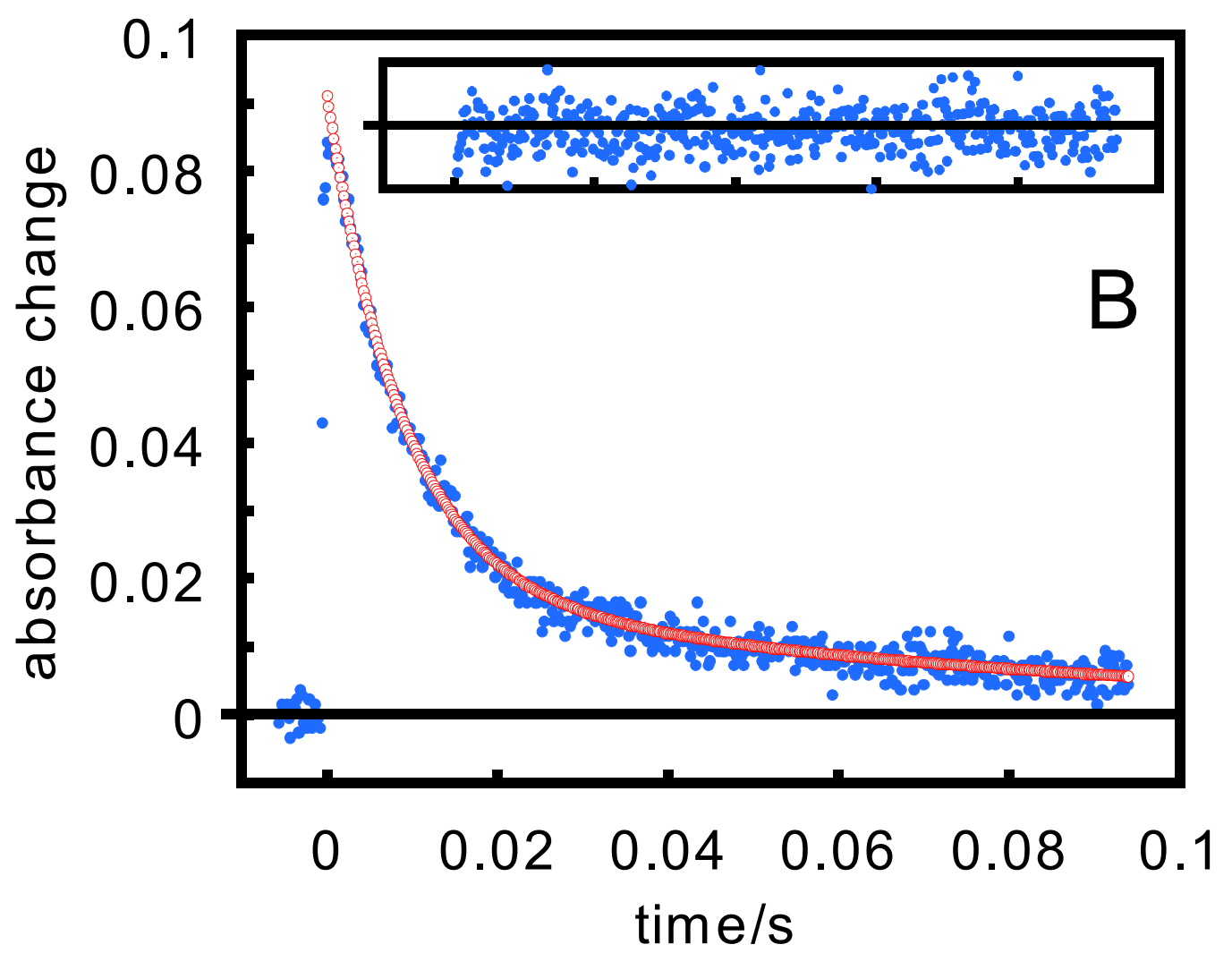




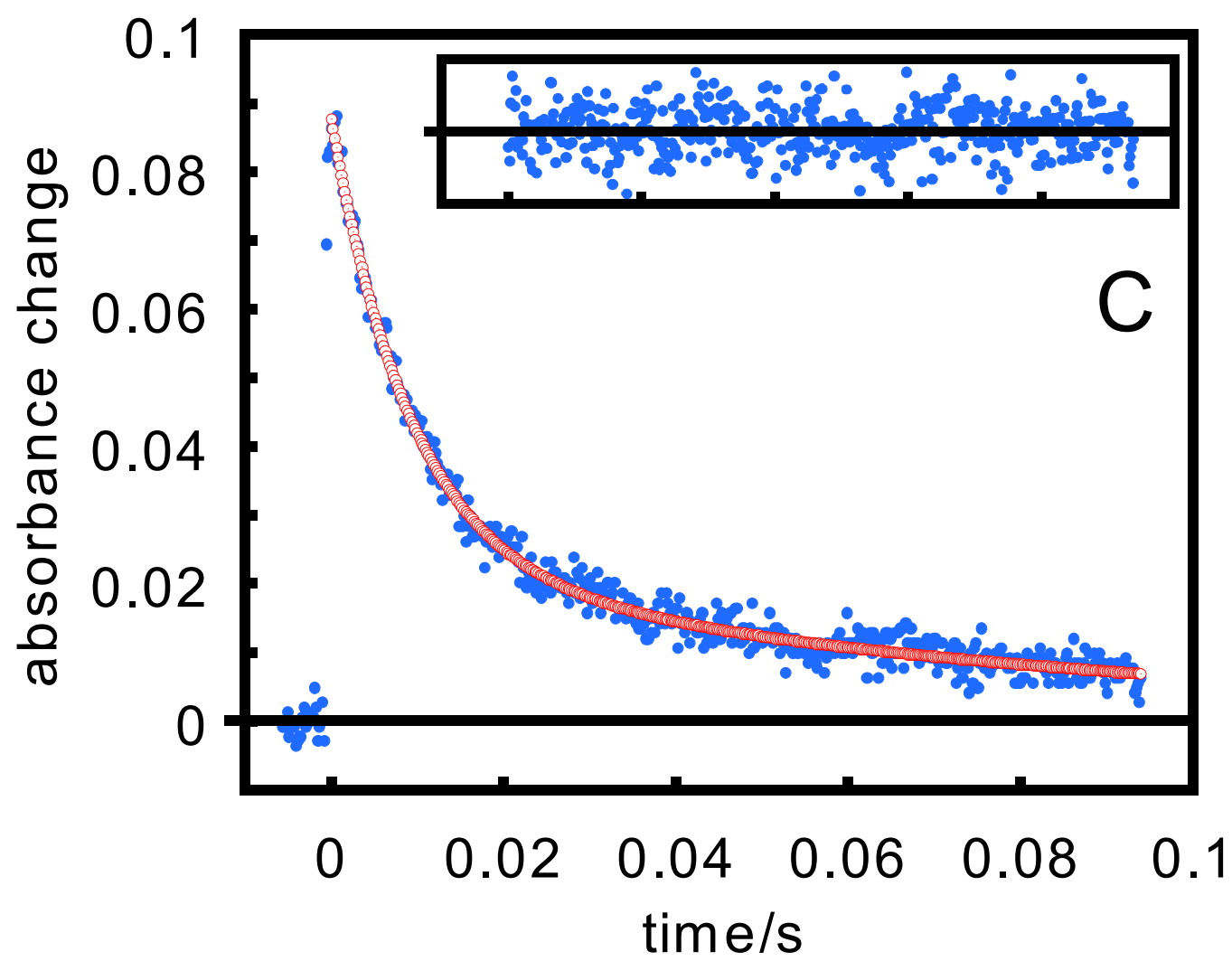

Figure S5. Kinetic absorption profiles for PhS-77DH ${ }^{\bullet}$ at $470 \mathrm{~nm}$ obtained at three different temperatures ((A) $323 \mathrm{~K},(B) 330 \mathrm{~K}(\mathrm{C}) 338 \mathrm{~K})$ and showing biexponential fits with residuals. The traces were obtained following $355 \mathrm{~nm}$ laser photolysis of $\mathrm{PhS}-\mathrm{SPh}(\sim 4 \times$ $\left.10^{-3} \mathrm{M}\right)$ in the presence of $77 \mathrm{DH}\left(\sim 2 \times 10^{-5} \mathrm{M}\right)$ in air-saturated benzene solution (laser energy $=1.3 \mathrm{~mJ}$ ). 


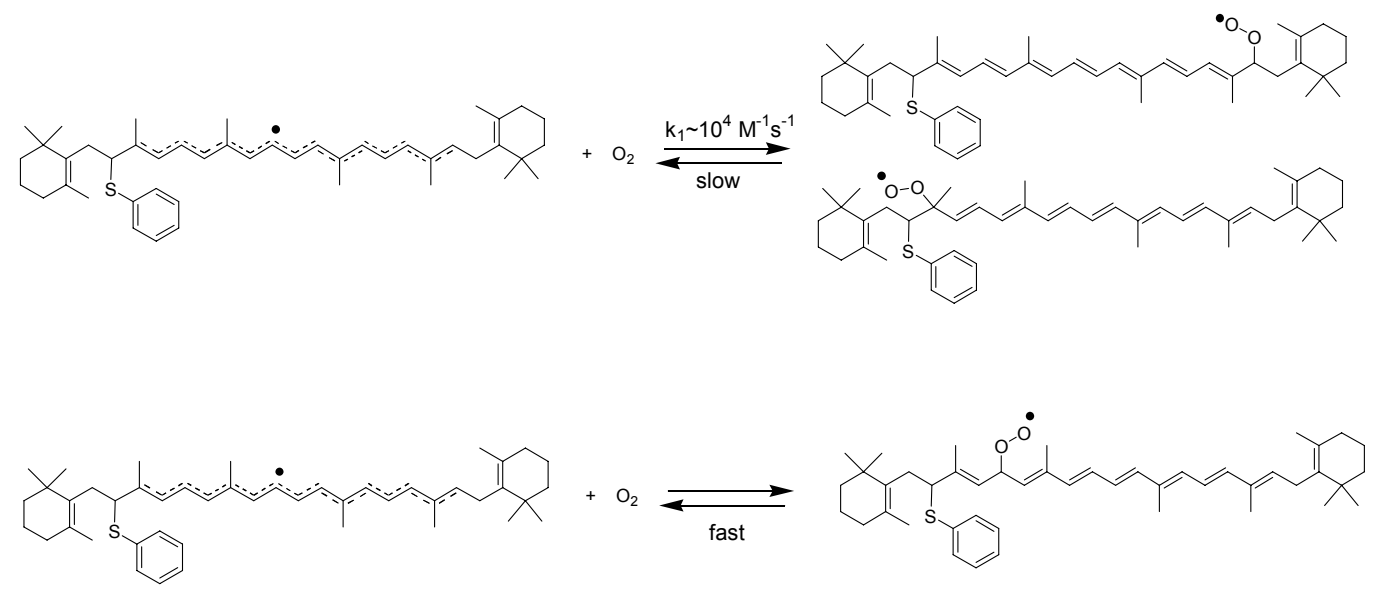

Figure S6. Reaction scheme illustrating terminal oxygen addition (top) and an example of non-terminal oxygen addition (bottom). 


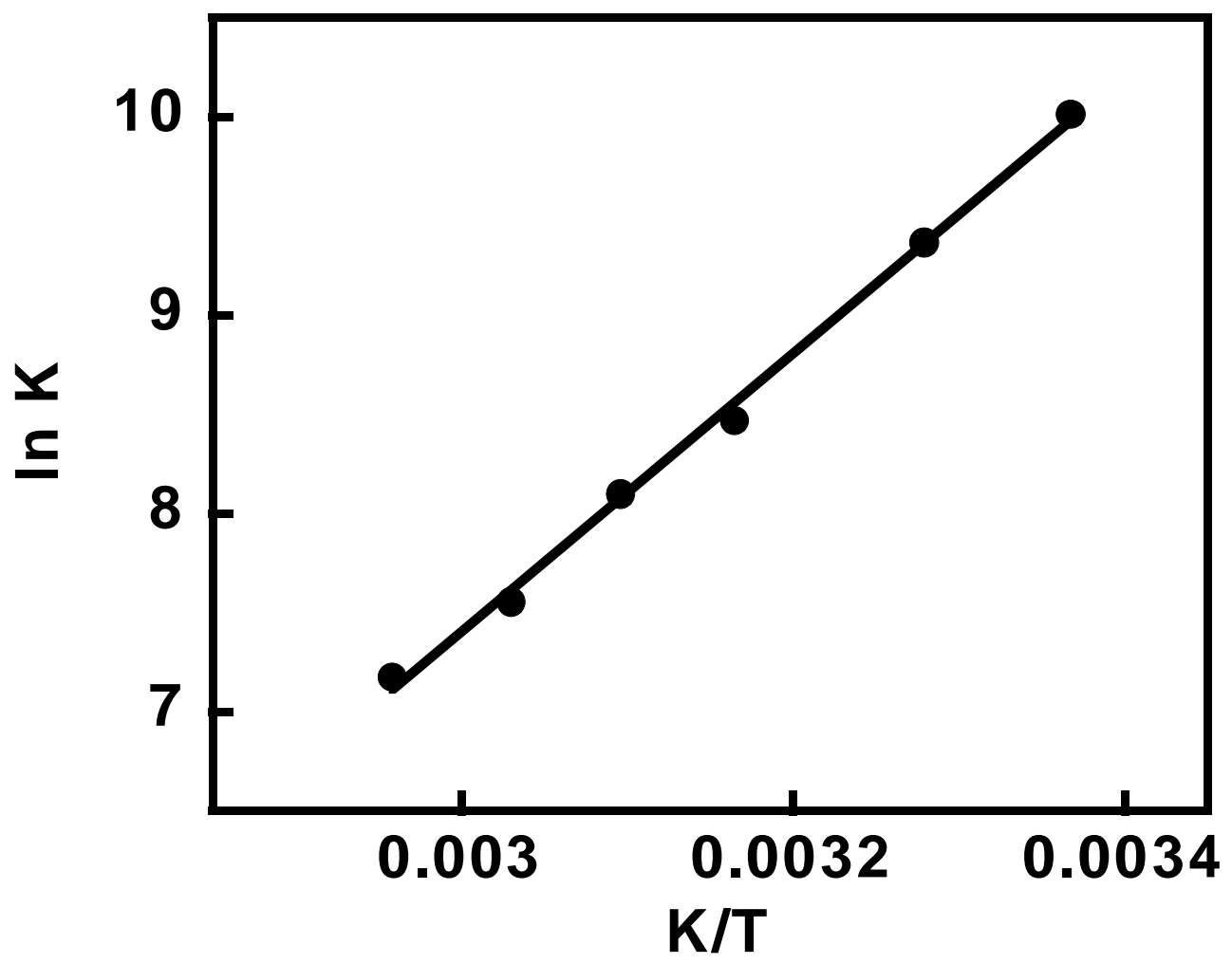

Figure S7. A plot of In $\mathrm{K}$ versus $1 / \mathrm{T}$ for the reversible addition of oxygen to $\mathrm{PhS}-77 \mathrm{DH}^{\bullet}$ in benzene (air saturated, $1.3 \mathrm{~mJ}$ ). 


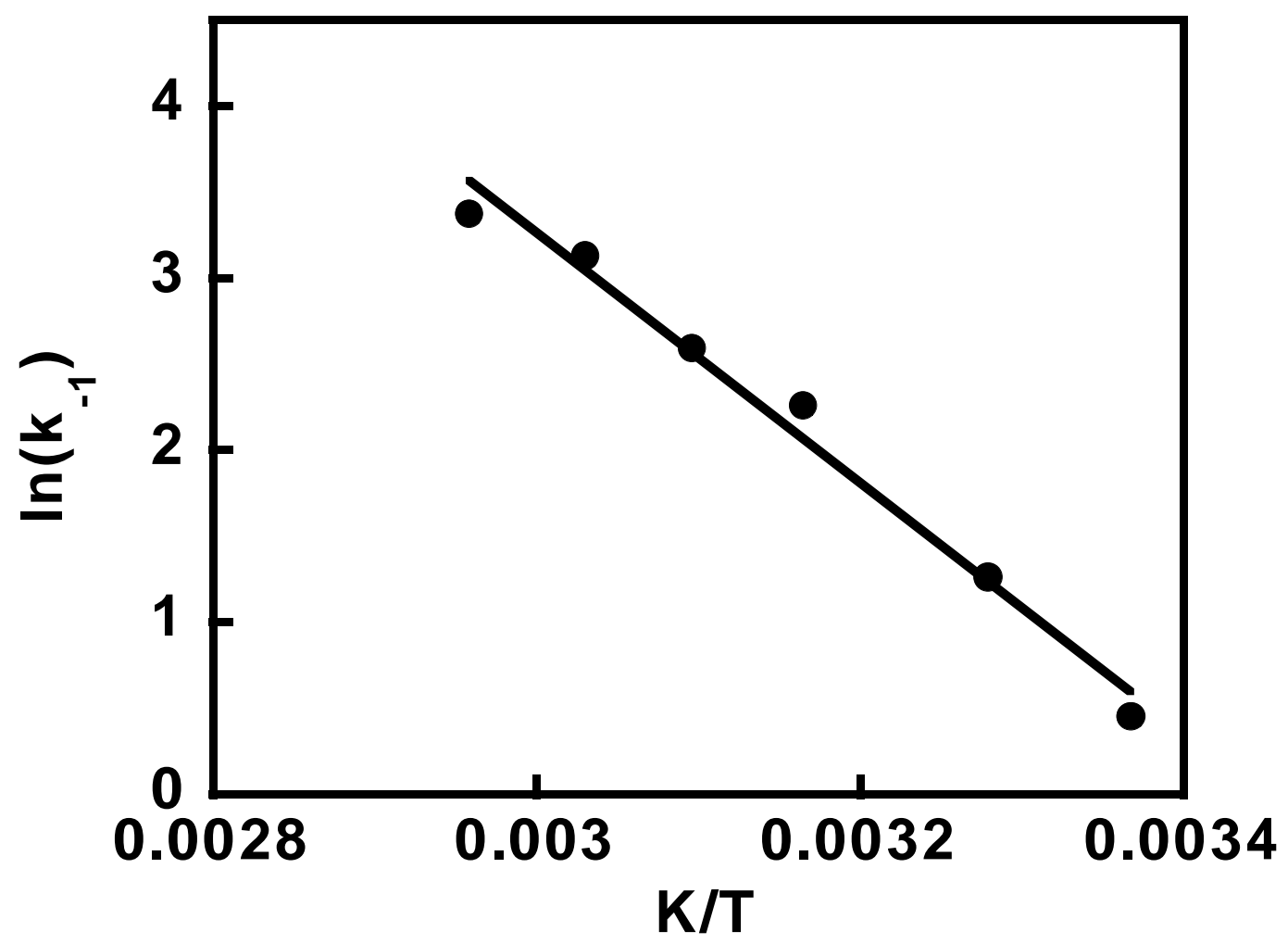

Figure S8. Arrhenius plot for the $\beta$-fragmentation reaction of PhS-77DH-OO' generated from $355 \mathrm{~nm}$ laser photolysis of PhS-SPh $\left(\sim 4 \times 10^{-3} \mathrm{M}\right)$ in the presence of $77 \mathrm{DH}(\sim 2 \times$ $10^{-5} \mathrm{M}$ ) in air-saturated benzene (laser energy $=1.3 \mathrm{~mJ}$ ). 


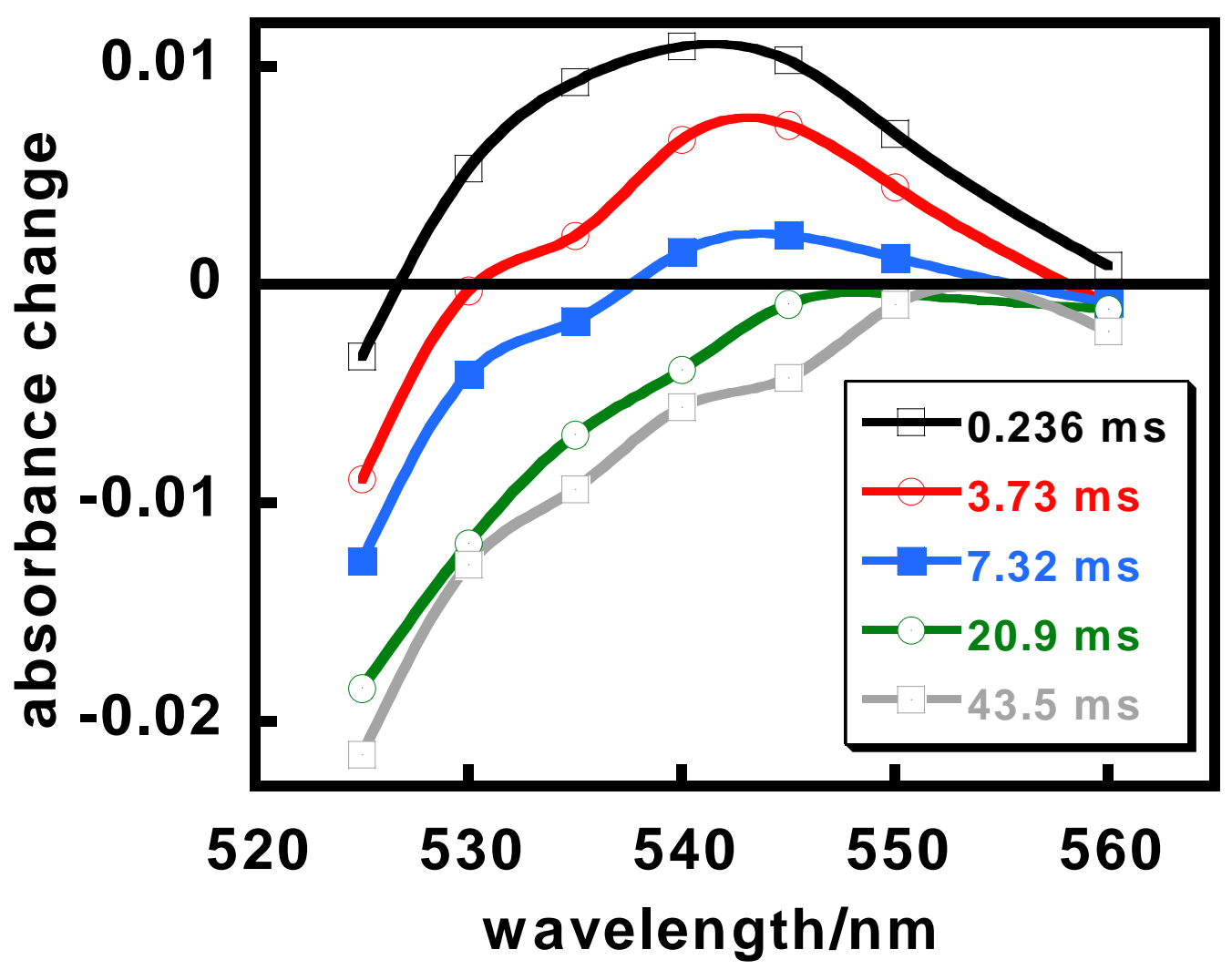

Figure S9. Transient difference absorption spectrum obtained following $355 \mathrm{~nm}$ laser photolysis (laser energy $\sim 4 \mathrm{~mJ})$ of an air-saturated benzene solution of PhS-SPh $(\sim 8 \times$ $\left.10^{-3} \mathrm{M}\right)$ in the presence $\beta$-CAR $\left(\sim 3 \times 10^{-5} \mathrm{M}\right)$. 


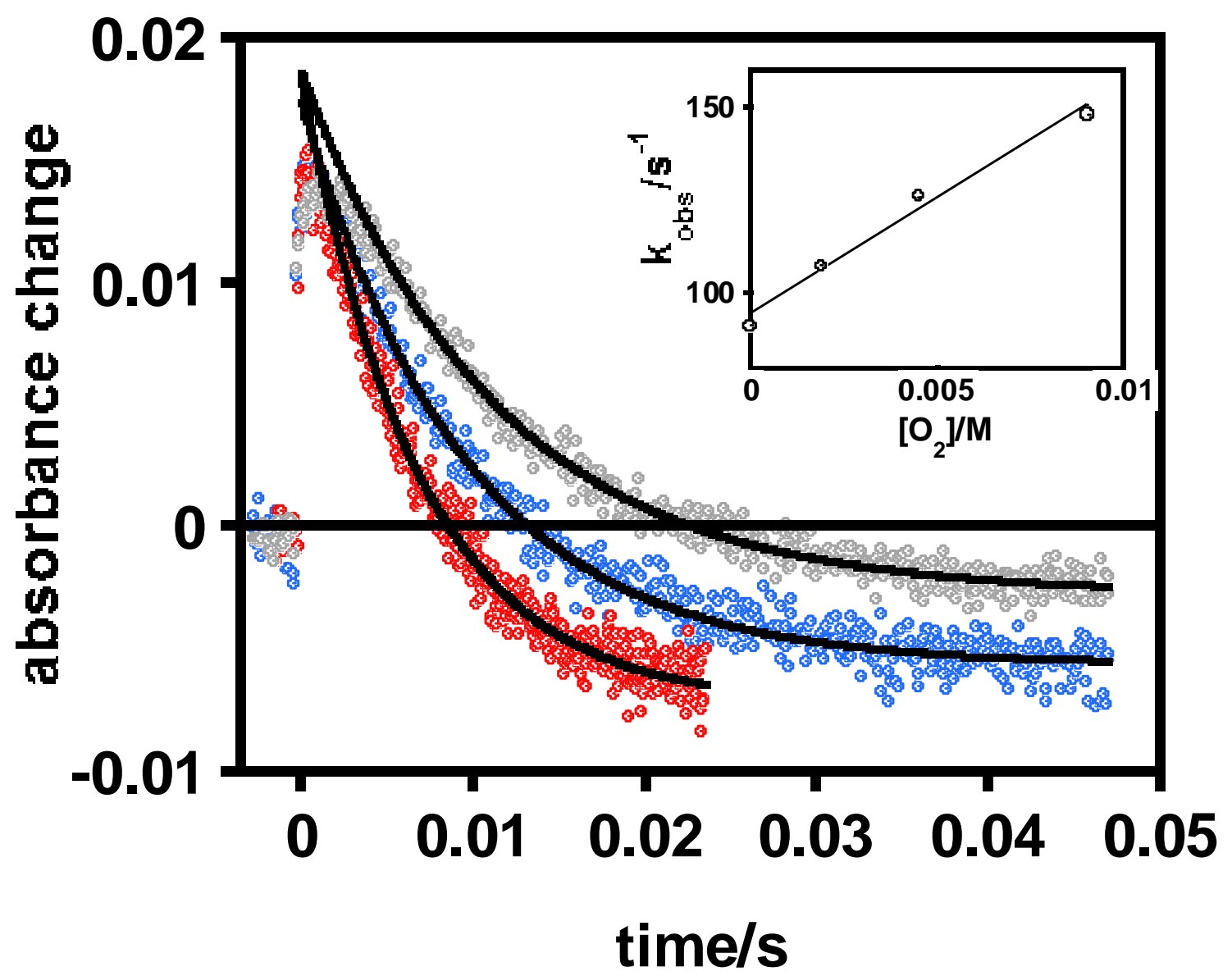

Figure S10. Kinetic absorption profiles at $540 \mathrm{~nm}$ obtained following $355 \mathrm{~nm}$ laser photolysis (laser energy $\sim 5 \mathrm{~mJ}$ ) of benzene solutions of PhS-SPh $\left(\sim 8 \times 10^{-3} \mathrm{M}\right)$ in the presence $\beta$-CAR $\left(\sim 3 \times 10^{-5} \mathrm{M}\right)$ at various oxygen concentrations (argon-saturated, airsaturated, oxygen-saturated). The inset shows a plot of the pseudo-first order rate constant $\left(k_{o b s}\right)$ for the decay of $\mathrm{PhS} \beta-\mathrm{CAR}^{\circ}$ (at $540 \mathrm{~nm}$ ) in benzene versus the concentration of oxygen. 
Table S1: Values of $A_{1}, A_{2}, k_{1}, k_{-1}, k_{o b s(1)}, k_{o b s(2)}, K$, and oxygen concentrations at different temperatures.

\begin{tabular}{ccccccccc}
\hline $\mathrm{T} / \mathrm{K}$ & $\mathrm{A}_{1}$ & $\mathrm{~A}_{2}$ & $\begin{array}{c}\left.\mathrm{O}_{2}\right] / 10^{-3} \\
\mathrm{M}^{11,12}\end{array}$ & $\begin{array}{c}\mathrm{K} / 10^{3} \\
\mathrm{M}^{-1}\end{array}$ & $\begin{array}{c}\mathrm{k}_{1} / 10^{4} \\
\mathrm{M}^{-1} \mathrm{~s}^{-1}\end{array}$ & $\begin{array}{c}\mathrm{k}_{-1} / \mathrm{s}^{-1} \\
\mathrm{k}_{\text {obs }(1)} / \\
\mathrm{s}^{-1}\end{array}$ & $\begin{array}{c}\mathrm{k}_{\text {obs }(2)} / \\
\mathrm{s}^{-1}\end{array}$ \\
\hline 338 & 0.0640 & 0.0233 & 2.10 & 1.31 & 3.8 & 29.3 & 109.7 & 13.5 \\
330 & 0.0733 & 0.0187 & 2.05 & 1.91 & 4.4 & 22.9 & 113 & 12 \\
323 & 0.0797 & 0.0120 & 2.02 & 3.29 & 4.4 & 13.4 & 102.4 & 6.7 \\
316 & 0.0820 & 0.0087 & 1.98 & 4.78 & 4.6 & 9.6 & 100.3 & 7.9 \\
305 & 0.0840 & 0.0037 & 1.93 & 11.7 & 4.2 & 3.6 & 83.9 & 5.9 \\
297 & 0.0720 & 0.0017 & 1.90 & 22.3 & 3.5 & 1.6 & 68.4 & $\mathrm{a}$ \\
\hline
\end{tabular}

${ }^{\text {a }}$ At room temperature $(\sim 297 \mathrm{~K})$, the transient profile fits better as first order plus baseline. In this case the amplitude and the residual absorption (baseline) values were assumed to be proportional to the concentrations of PhS-77DH-OO* and PhS-77DH" respectively. 